ARCHIVO ESPAÑOL DE ARTE, LXXXII, 326

ABRIL-JUNIO 2009, pp. 194-226

ISSN: 0004-0428

\title{
VARIA
}

\section{LA OBRA DE FRANCISCO GIRALTE EN VALLADOLID}

Se reconstruye la actividad vital y artística del escultor Francisco Giralte, discípulo de Alonso Berruguete, en Valladolid. Se formulan dos nuevas atribuciones al artista: un Crucifijo del Palacio Real y la Virgen de la Pasión.

Palabras clave: Escultura del siglo XVI.

The author analyses the life and artistic activity in Valladolid of the sculptor Francisco Giralte, disciple of Alonso Berruguete. Also presented are two new attributions to the artist, a Crucifix in the Royal Palace and the Virgin of the Passion.

Key words: 16 th century sculpture.

La relación del escultor Francisco Giralte con la ciudad de Valladolid aparece constatada tanto por algún dato documental, que así nos lo indica, como por varias obras vallisoletanas que pueden adscribirse al mismo, pese a que cuando tiene lugar el pleito por el retablo de Nuestra Señora de la Antigua, se declara vecino de Palencia, en donde debió vivir hasta que a mediados de siglo emprende su asentamiento definitivo en Madrid.

Consta que trabajó en el taller de Berruguete, al menos como oficial, sin que podamos concluir con certeza que antes hubiera sido aprendiz suyo. Al menos se precisa su estancia aquí entre 1532 y la Navidad de 1534, tal y como se indica en el pleito que tuvo su maestro en 1535 con el boticario Íñigo de Santiago, quien había puesto de aprendiz de pintor a su hijo Jerónimo y no estaba de acuerdo con la formación de este oficio que se le había dado al mismo. En el litigio, se cita a Giralte como "criado" de Berruguete. Es decir como oficial. Ya no se encontraba en 1535 en el taller, pues no declara en el mencionado pleito como testigo, tal y como hacen otros miembros del mismo. Probablemente fuera a asentarse a Palencia, en donde luego aparecerá trabajando ${ }^{1}$. Pero tampoco puede excluirse que estuviera trabajando en otro punto geográfico.

Sin embargo, en 1537 consta que estaba en la ciudad de Valladolid. Ese año aparece de testigo junto a Alonso Berruguete y un personaje llamado Pedro Campo, en un poder que otor ga la Cofradía del Rosario a favor del cofrade Hernando Bernaldo. Se dice que todos ellos eran "estantes y habitantes en esta villa", por lo que se puede suponer, si el escribano tomó bien las referencias personales, que Giralte había vuelto a asentarse en la ciudad de Valladolid. Es probable que nuestro escultor volviera a colaborar con su maestro en las obras que tenía éste entre manos en torno a ese año, de la misma manera que, a partir de 1539, volverá a hacerlo en la sillería alta del coro de la catedral de Toledo. Hoy sabemos que muchos maestros independientes, que contratan sus propias obras, no dudaban en ponerse circunstancialmente al servicio de otro más importante, si

\footnotetext{
${ }^{1}$ A Lonso Cortés, N.: Datos para la biografía artística de los siglos XVI y XVII. Boletín de la Real Academia de la Historia, 1922, pp. 23-25. Analizados estos extremos referentes al trabajo en el taller de Berruguete, en PARRADO DEL Olmo, J. M.: Los escultores seguidores de Berruguete en Palencia. Valladolid, 1981, p. 112.
} 
ello les resultaba beneficioso. Al margen de la ganancia económica, debían influir en esta decisión tanto la posibilidad de estudiar nuevos modelos del maestro, como obtener el prestigio de ser un colaborador habitual de un artista reconocido.

Al respecto de la cofradía del Rosario, la misma lindaba con el palacio de don Francisco de los Cobos y doña María de Mendoza, y los mismos reconstruyeron el edificio y la dotaron de obras de arte, a cambio de utilizarla como capilla particular. Cuando la emperatriz doña Isabel de Portugal, esposa de Carlos V, residió en el palacio de aquéllos entre 1536 y 1538, asistía a los cultos en la misma y se sabe que costeó "un retablo y tribuna y un pasadizo y puerta por lo bajo para entrar a la dicha iglesia"2. A partir de entonces recibió el nombre de Capilla Real. Agapito y Revilla relacionó la actuación como testigos de Berruguete y Giralte en el citado poder de la Cofradía con el pago de un retablo para la misma por parte de Isabel de Portugal, y apuntaba la posibilidad de que éste pudiera haber sido ejecutado por ambos ${ }^{3}$. Nada tendría de extraño que Berruguete se encar gara del mismo, si se tiene en cuenta su trabajo habitual para la Corte. Precisamente en 1537 se le concedía a éste autorización real para poner sustituto en el car go de escribano de la Chancillería de Valladolid, "por estar ocupado en algunas cosas de nuestro servicio". Ese año el artista había contratado también el retablo de don Diego de la Haya en la iglesia de Santiago, y la acumulación de trabajo le obligaría a contar con colaboradores hábiles para poder llevarlo a cabo, de manera que pudo tener a Francisco Giralte como encargado del trabajo principal de este retablo para la Capilla Real, siguiendo sus modelos. El retablo sufrió diversos arreglos a lo lar go del siglo XVII, a través de los cuales se hacen algunas descripciones del mismo ${ }^{4}$.

En cualquier caso, el retablo fue sustituido por otro neoclásico, tal y como puede verse en una fotografía antigua que lo muestra in situ $u^{5}$. Este retablo es el que hoy se encuentra en el oratorio del Palacio Real, adonde se trasladó cuando la capilla fue derribada en $1944^{6}$. Al parecer, el retablo procedía del Monasterio de Nuestra Señora de Prado, de donde lo hizo trasladar el infante Francisco Manuel de Paula Antonio, quien vivió en el Palacio entre 1847 y $1850^{7}$. Es de madera policromada, imitando mármol. Su traza es muy elegante, y presenta claras diferencias con los retablos neoclásicos vallisoletanos, por lo que pudo ser trazado por un maestro cortesano.

En la citada fotografía, se advierte que en el ático de este retablo se encontraba el símbolo de la Venerable Orden Tercera, pues en 1794 los franciscanos descalzos del convento de San Diego obtuvieron permiso de Carlos IV para fundar esta orden en la capilla. Hoy sin embar go tiene un bello crucifijo de madera policromada, cuya procedencia es desconocida, pues fue colocado en el momento en que se trasladó el retablo desde la Capilla Real, en 1944, pues el que existía en ésta no cabía en el ático del mismo ${ }^{8}$. Quienes se han referido a esta pieza, se han limitado a decir que era un crucifijo del siglo $\mathrm{X} \mathrm{VI}^{9}$.

\footnotetext{
2 Sobre la capilla y la cofradía ver: ALCOCER, Mariano: "El Rosarillo". Boletín de la Comisión de Monumentos. 5, 1927, pp. 33-47; Agapito y Revilla, J.: "La Capilla Real de Valladolid". Boletín de la Sociedad Española de Excursiones, 1944, p. 124; J. U RREA FERnÁNDEZ: "El Palacio Real de Valladolid”. Boletín del Seminario de Arte y Arqueología, XL-XLI, 1975, pp. 241-258; Rivera Blanco, J. J.: El Palacio Real de Valladolid (Capitanía General de la VII Región Militar). Valladolid, 1981, pp. 109-1 15.

${ }^{3}$ A gapito y Revilla, J.: op. cit., p. 124.

${ }^{4}$ P Érez Gil, J.: El Palacio Real de Valladolid. Sede de la Corte de Felipe III (1601-1606). Valladolid, 2006, pp. 354-358.

5 Publicada por J. Agapito y Revilla: op. cit., id.

${ }^{6}$ P Érez Gil, J.: El Palacio Real..., op. cit., pp. 345 y 359.

${ }^{7}$ P Érez Gil, J.: El Palacio Real..., op. cit., p. 358, nota 1060.

${ }^{8}$ P Érez Gil, J.: El Palacio Real..., op. cit., p. 345.

${ }^{9}$ M artín GonzÁlez, J. J.: Catálogo Monumental de la Provincia de Valladolid. Monumentos civiles de la ciudad de Valladolid. Valladolid, 1976, p. 40; R ivera Blanco, J. J.: El Palacio Real de Valladolid (Capitanía General de la VII Región Militar). Valladolid, 1981, p. 151; C ARRACEDo P RIMO, J.: Patrimonio histórico-artístico del Palacio Real de Valladolid. Valladolid, 1993.
} 


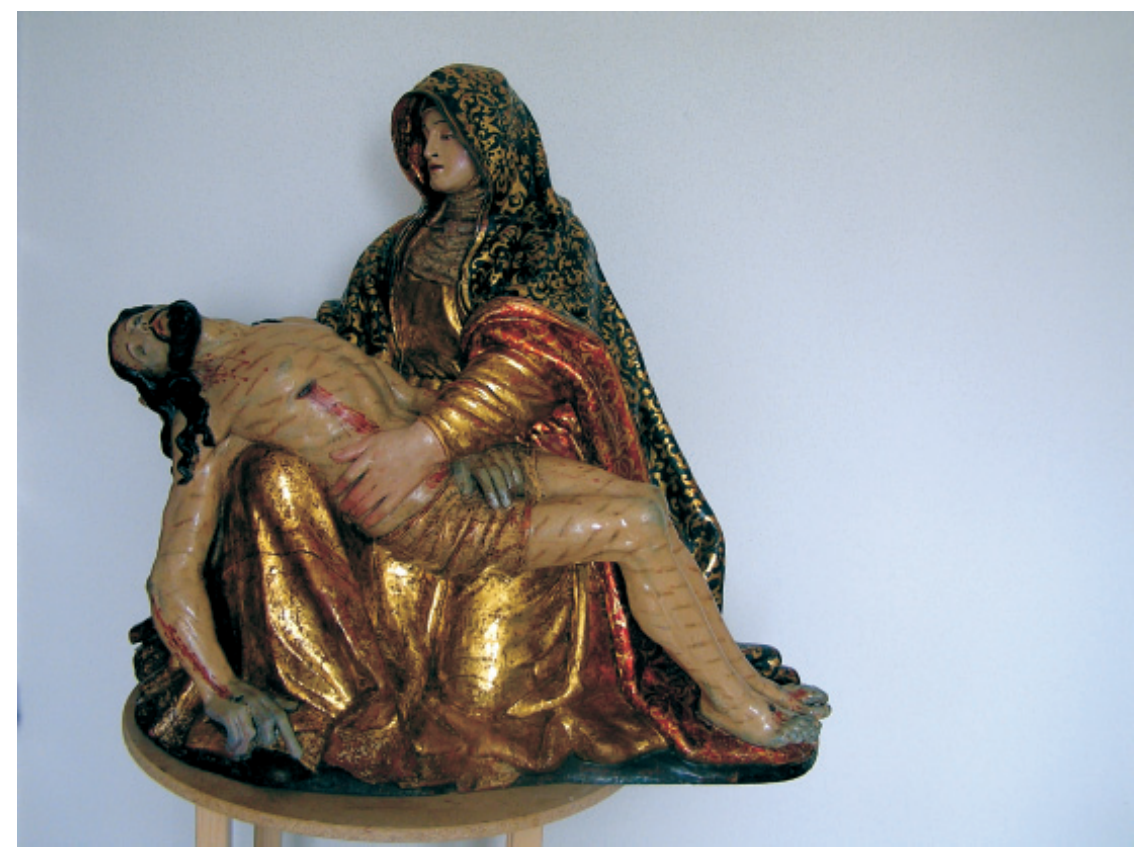

Fig. 2. Francisco Giralte. Virgen de la Pasión (conjunto). Valladolid, Cofradía de la Pasión.

La escultura es una pieza de buena calidad. Presenta un canon corto, con un modelado muy suave de las formas corporales, estableciendo una suave gradación de planos entre el torso y el vientre. Las piernas se disponen paralelas, sin angulosidades expresionistas. De igual manera, aunque se trata de un crucifijo muerto, en la cabeza no aparece ningún patetismo exagerado, sino que descansa placidamente sobre el pecho. Un largo mechón de pelo apelmazado cae por delante del hombro derecho. Tiene corona de espinas tallada. En los rasgos fisiognómicos es característico el arqueo de las cejas, según la tipología berruguetesca. El paño de pureza presenta un nudo en el costado izquierdo, que crea un gran doblez en la parte superior , y cae ampliamente hacia abajo, casi hasta las rodillas. El paño es ancho y está tallado con finos pliegues paralelos.

Si bien ya se ha indicado la filiación berruguetesca de la escultura, la interpretación es distinta a la del estilo de éste, tanto por el canon, como por la suavidad con la que está interpretado. La calidad de la imagen indica que es de un maestro importante, y con el que presenta mayores relaciones es con el estilo de Francisco Giralte, tanto por la suavidad del tratamiento formal, como por la placidez de la expresión. No es usual el tipo de nudo del paño de pureza en el escultor , que prefiere anudarlo por detrás, pero hay algunos crucifijos que le he atribuido, que sí presentan esta modalidad, como son los de La Pedraja (V alladolid), Villamediana (Palencia) y el Carmelo de Tordesillas. Este tipo de anudamiento lo emplean además otros escultores del área palentina, en especial el bigarnista Juan Ortiz el Viejo I, de donde lo pudo tomar Giralte para estas obras propias.

Aunque no podamos pensar que el crucifijo sea un resto del retablo de la capilla Real, la fecha del mismo no estaría muy alejada del momento en que se ejecutó el mismo, es decir , en torno a 1540.

Se advierte que Francisco Giralte realizó trabajos para cofradías penitenciales de Valladolid. Hace poco se le ha atribuido el Paso procesional de la Entrada Triunfal de Jesús en Jerusalén, conocido popularmente como "la Borriquilla", perteneciente a la Cofradía de la 
Vera Cruz. Este paso tiene el gran interés de ser el más antiguo de los conservados, puesto que responde a la técnica de papelón. Es decir , las figuras se construyen en forma de maniquí, con telas encoladas y pintadas al óleo, y sólo se tallan cabezas, manos y pies. Así eran los pasos procesionales, tal y como los describía Pinheiro da Veiga en 1605, hasta que fueron sustituidos a lo lar go del siglo XVII por figuras completas de madera policromada a tamaño natural ${ }^{10}$.

Otra escultura para la Cofradía de la Pasión que atribuyo al escultor es la Virgen titular de la misma. La escultura mide $78 \times 81 \times 45 \mathrm{cms}$. Estuvo situada en el retablo mayor de la iglesia penitencial, hasta que la misma fue despojada de sus bienes, entre los cuales se encontraba su edificio. Este retablo desaparecido fue concertado en 1657 por Antonio y Alonso de Villota y el escultor Francisco Díez de Tudanca, con la novedad de ser el primero en Valladolid en el que conste que se usaban columnas salomónicas ${ }^{11}$. Se exhibía con manto y corona, tal y como pueden verse en dos planchas de cobre para grabar de los siglos XVIII y XIX respectivamente, y en un grabado popular ${ }^{12}$. El historiador Canesi indicaba que la imagen había sido donada a la cofradía por el diputado de la misma D. Diego Sánchez Pintado ${ }^{13}$. Ya era citada en 1553. Cuando la cofradía tuvo que abandonar su iglesia en 1926, sus imágenes sufrieron un proceso de depósito en distintos lugares, tales como el Museo Nacional de Escultura, la iglesia parroquial de la Magdalena y el convento de San Quirce y Santa Julita. Precisamente en 1987 se pretendió identificar la imagen titular de la Cofradía con una Piedad situada en dependencias interiores de este monasterio ${ }^{14}$

Aunque la misma también pertenece a la Cofradía, la Virgen de la Pasión auténtica fue identificada por Luis Luna, quien supone que fue el primer paso procesional que tuvo. Indica que en 1556 desfilaba acompañada por San Juan, la Magdalena, los dos ladrones y unos ángeles, quizá figuras de papelón ${ }^{15}$. La restauración de la imagen realizada en 2005 por Doña Cristina Parrado ha restituido a la escultura un aspecto próximo al primitivo. En especial, se han restituido algunas partes dañadas, como algunas zonas del manto de la Virgen, los agujeros ocasionados por la acción de clavos introducidos en la imagen, y , en especial la cabeza del Cristo, que tenía pérdidas de masa volumétrica, en especial en la talla de nariz y boca ${ }^{16}$. Al eliminarse los repintes, se ha restituido la policromía original, en la que se aprecia carnación a pulimento. La túnica se presenta sólo recubierta con el pan de oro sobre el bol, mientras que el manto tiene sencillos motivos esgrafiados en los estofados, sobre fondo azul en el anverso y rojo en el reverso. El paño del Cristo presenta motivos lineales y punteados sobre el predo-

${ }^{10}$ La atribución a Giralte en J. M. P ARRADO DEL Olmo: "La entrada triunfal de Jesús en Jerusalén ('La Borriquilla')". Ficha n. ${ }^{\circ} 4$ del Catálogo El Árbol de la Vida. Las Edades del Hombre. Segovia, 2003, pp. 55-57. Se remite a este estudio.

11 E. García Chico: Documentos para el estudio del arte en Castilla. Escultores. Valladolid, 1980, pp. 246, 249; J. J. MarTín GonZÁlez: El retablo barroco en España. Madrid, 1993, p. 101.

${ }^{12}$ Han sido estudiadas por J. J. M ARTín GonZÁlez: "Una plancha de grabado de la Virgen de la Pasión, de Valladolid”. Boletín del Seminario de Arte y Arqueología. Tomo XLVIII, 1982, pp. 405-408; B. G ARCía VeGA: Estampas de imágenes vallisoletanas. Boletín del Seminario de Arte y Arqueología. Tomo LI, 1985, pp. 397-398; M. R. F ERNÁNDEZ GonzÁlez: "Los grabados de las imágenes de la Semana Santa de Valladolid". En Gregorio Fernández y la Semana Santa de Valladolid. Valladolid, 1986, pp. 12-18.

13 Citado por M. R. F ERNÁNDEZ GonZÁLEZ: “Los grabados...”, op. cit., p. 12.

${ }^{14}$ M artín González, J. J. y D e la Plaza Santiago, F. J.: Catálogo Monumental de la provincia de Valladolid. Monumentos religiosos de la ciudad de Valladolid (conventos y seminarios). Valladolid, 1987, p. 193, fig. 717.

${ }^{15}$ L UNA, L.: "Notas sobre la historia de la Cofradía de la Pasión II". En Boletín Informativo. Cofradía de la Sagrada Pasión de Cristo, n. ${ }^{\circ}$ 4, abril de 1993, p. 4.

${ }^{16}$ P arrado Parrado, C.: "Restauración de la imagen de Ntra. Sra. De la Pasión". En Boletín Informativo. Cofradía de la Sagrada Pasión de Cristo, n. ${ }^{\circ}$ 1, 2. ${ }^{a}$ época, Valladolid, 2005, pp. 28-30. 


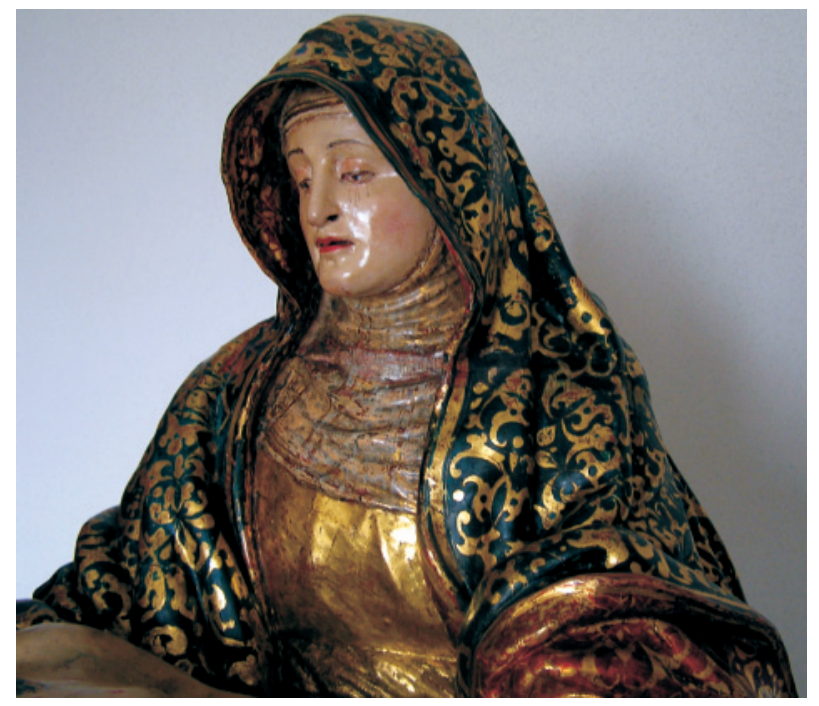

Fig. 3. Francisco Giralte. Virgen de la Pasión (detalle). Valladolid, Cofradía de la Pasión.

Fig. 4. Francisco Giralte. Virgen al pie de la Cruz, en el Calvario de Villarmentero de Campos (Palencia).

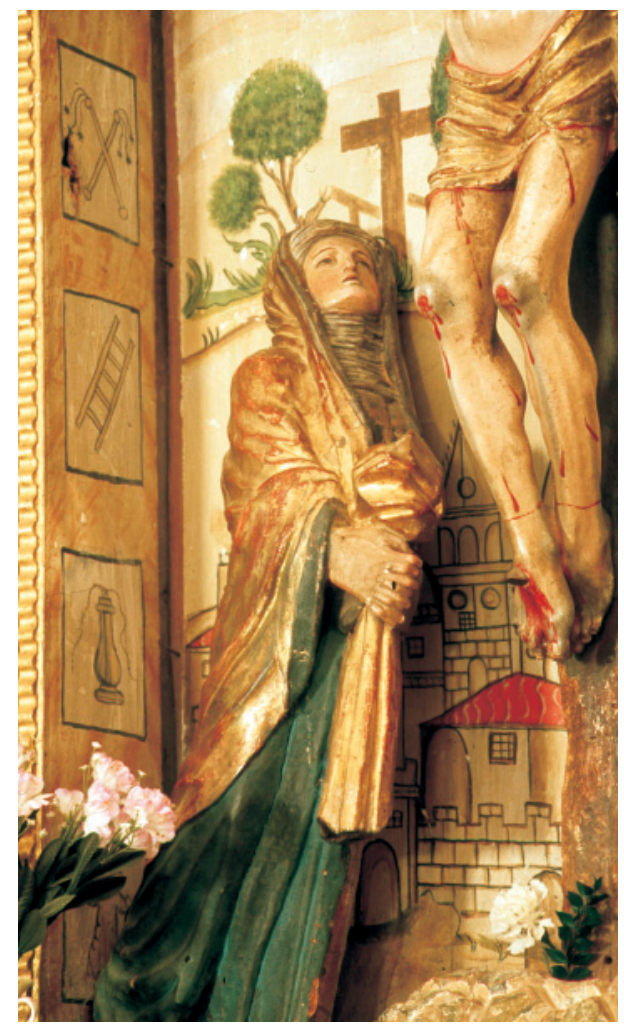

minante dorado. A destacar la sutileza del trabajo de las huellas de los latigazos, pintadas al óleo. No cabe duda que se trata de una policromía usada habitualmente a lo lar go del segundo cuarto del siglo XVI.

Pasando ahora al análisis de la escultura, se aprecia que es una obra de calidad, en la que la composición está muy bien resuelta, pues se evita la frontalidad rígida que este tipo de iconografías dedicadas a la Piedad comportan en algunos casos. Para ello, el escultor ha dispuesto la pierna derecha de la Virgen más alta y adelantada que la izquierda, por lo que el cuerpo de la misma gira hacia su lado derecho y al mismo tiempo aparece mirando hacia la cabeza de su Hijo, en una actitud llena de veracidad sentimental. Esta disposición de las piernas de la Madre obliga al cuerpo de Cristo a crear una composición en doble curva, con el torso muy quebrado sobre la pierna derecha de la Virgen, lo que aporta un efectismo dramático, al mismo tiempo que refleja adecuadamente la representación de un cuerpo inerte. Queda la duda de si el escultor pudo inspirarse en una imagen anterior de finales del siglo $\mathrm{XV}$, momento en el que es habitual que los Cristos tengan los cuerpos muy crispados. La anatomía es de muy buena calidad. El Cristo presenta un canon ligeramente alar gado y las superficies están trabajadas con habilidad, dentro de un concepto de formas muy marcadas, en la línea de Berruguete, si bien con mayor suavidad que éste. De igual manera, la cabeza, de ojos dispuestos en diagonal y rasgos afilados apuntan a un maestro relacionado con el gran escultor . Presenta barba apelmazada y bífida, mientras el cabello cae sobre el hombro derecho y la espalda en mechones curvos y apelmazados. 
Se puede indicar que la escultura de la Virgen de la Pasión presenta una interpretación manierista, en la que se ha templado la aparatosidad dramática de Alonso Berruguete, pues tanto la anatomía como la expresión de las cabezas de las dos figuras es más suave que las empleadas por aquél. Esta tendencia hacia una mayor delicadeza es habitual en los seguidores del maestro de la década de los años cuarenta, en relación con el trabajo en la sillería alta del coro de la Catedral de Toledo ${ }^{17}$. Precisando más en los rasgos morellianos del estilo de esta escultura, creo que se puede formular una atribución convincente al escultor Francisco Giralte. Hay muchos aspectos de esta imagen habitualmente empleados por este escultor . Así la cabeza de la Virgen presenta un perfil cuadrático, con la mandíbula prominente y va envuelta en una toca situada por debajo del manto, que se ciñe al cuello y parte superior del busto, tal y como aparece en otras interpretaciones virginales del autor. En especial tiene claras relaciones con la Virgen del Calvario de Villarmentero de Campos (Palencia), la Asunción del retablo mayor de esta misma localidad, la Virgen dispuesta de pie encima del banco del retablo de Cisneros (Palencia) o las distintas figuras femeninas de los relieves del Descendimiento y Llanto sobre Cristo muerto del retablo de la Capilla de los Corral en la iglesia de la Magdalena de Valladolid. Con estas obras tiene también relaciones en la caída de los plegados que forman bordes lineales que se quiebran al llegar al suelo. El paño del Cristo es similar a otros empleados por Giralte, habitualmente muy ceñidos al cuerpo y con finos pliegues paralelos. En cuanto a la cabeza, la caída de los cabellos y los rasgos de la cara se acercan a los crucifijos atribuidos en Frómista (Palencia), si bien la anatomía presenta alguna variedad con respecto a otras interpretaciones conocidas del escultor, que emplea generalmente unas formas menos marcadas ${ }^{18}$. Otro aspecto que se debe tener en cuenta para relacionarla con Francisco Giralte es la forma de las manos, excesivamente desproporcionadas en relación con las dimensiones del cuerpo, por su tamaño excesivo. En algunas de sus obras de esta etapa de su actividad artística con la que estamos relacionando la imagen de la Virgen de la Pasión, es habitual que este escultor tenga estas desproporciones, quizá por un excesivo trabajo de taller, necesario para acometer sus numerosos encar gos. Así sucede en los retablos de Cisneros, Villarmentero de Campos o de San Ginés de Villabrágima.

Es problemático dar una fecha exacta para la imagen. Sabemos que la misma estaba realizada ya en 1553, como indicó en su momento Martí y Monsó ${ }^{19}$. Acerca de las otras obras que acabo de poner en relación con la Virgen de la Pasión, no hay fechas concluyentes sobre las mismas, salvo para el retablo de Cisneros y el del Doctor Corral, que son citados como hechos en las declaraciones del testigo Jerónimo Vázquez en el Pleito que sostuvo Giralte con Juan de Juni por la ejecución del retablo mayor de la iglesia de la Antigua, y por lo tanto anteriores a $1547^{20}$. Al menos desde 1550, el escultor figura ya como vecino de Madrid, en donde va a vivir a raíz de sus obras para la capilla del Obispo de esta ciudad. Esto indica que sería difícil que pudiera contratar la Virgen desde su residencia madrileña. De 1539 a 1542, estuvo colaborando con Berruguete en la sillería toledana. Por lo tanto, habrá que situarla en torno a los años 1543-1550, sin que se pueda precisar más al respecto. El hecho de que no aparezca citada entre las obras realizadas por Giralte por los testigos del mencionado pleito no indica que no la tuviera ya hecha, pues al

${ }^{17}$ Ver al respecto de esta evolución, que incluso se puede rastrear en el Berruguete de su etapa final y no sólo en sus discípulos: PARRADO DEL Olmo, J. M.: "El diálogo entre las tendencias escultóricas castellanas a mediados del siglo XVI". ACADEMIA. Boletín de la Real Academia de Bellas Artes de San Fernando, n. ${ }^{\circ}$ 81, 1995, pp. 251-273. Idem: Las tendencias de la escultura vallisoletana a mediados del siglo XVI (1539-1562). Valladolid, 2004.

18 Sobre estas obras citadas del escultor, puede verse: P ortela S Andoval, F. J.: La escultura del Renacimiento en Palencia. Palencia, 1977, pp. 250-294; P ARRAdo Del Olmo, J. M.: Los escultores..., op. cit., pp. 109-191; Idem: "Sobre algunas esculturas del siglo XVI". Boletín del Seminario de Arte y Arqueología, LXIX-LXX, 2003-2004, pp. 303-320.

${ }^{19}$ M ARTí Y Monsó, J.: Estudios..., op. cit., p. 498, nota n. ${ }^{\circ} 2$.

${ }^{20}$ M ARTí Y Monsó, J.: Estudios..., op. cit., pp. 386 y ss. 
ser un litigio por un retablo, aquéllos sólo citan algunos de los retablos realizados por el maestro como señal de autoridad contratante en este tipo de trabajos.

A través de estas obras, se puede pensar que Giralte, aunque estaba asentado en Palencia, también realizaba trabajos escultóricos para la ciudad de Valladolid. No se puede olvidar que la ciudad pertenecía al obispado palentino, y que por ello podían trabajar en la misma maestros de éste. Pero sobre todo, Giralte debió aspirar a asentar su taller en la ciudad del Pisuer ga, mucho más cosmopolita que la de Palencia, en donde los encar gos daban mayor prestigio y rendimiento económico. Éste fue el motivo de que aprovechara el cúmulo de circunstancias que se dieron en torno a 1545 para que la parroquia de Santa María de la Antigua decidiera revocar al contrato con Juan de Juni para hacer el retablo mayor de su iglesia, y se presentara como rival de éste en la ejecución del mismo. Era su oportunidad para asentarse definitivamente en la ciudad. Pero además suponía el trabajo en una obra de gran enver gadura, sobre la que poder asentar su prestigio en la ciudad, pues no se debe olvidar que hasta ese momento, había trabajado en la ciudad a la sombra de Berruguete, en obras aisladas para cofradías penitenciales y en un retablo para una capilla funeraria. Pero en lo referente al retablo de la Antigua no halló la protección de Berruguete, quien parece haber entablado pactos con Juni, quizá para proteger a su sobrino Inocencio, y Giralte no consiguió su objetivo, si bien la ejecución del conjunto escultórico de la Capilla del Obispo de Madrid, su obra maestra, le llevará a asentarse definitivamente en esta ciudad ${ }^{21}$.

No puede extrañar que su cuñado Manuel Álvarez, quien también debía tener aspiraciones a trabajar en Valladolid, declare como testigo en contra de Inocencio Berruguete en el pleito de éste con don Pedro González de León en 1553, y a través de sus declaraciones se aprecie animadversión hacia los Berruguete 22 .

De esta manera, a la única obra conocida por el Pleito de la Antigua que Giralte había hecho en Valladolid, es decir, el retablo de la Capilla del Doctor Corral en la iglesia de la Magdalena, se añaden ahora nuevas esculturas del maestro en la misma ciudad ${ }^{23}$. En cuanto al retablo de don Luis de Corral, importante personaje vallisoletano, puesto que además de catedrático de Cánones de la universidad vallisoletana, y oidor de la Chancillería, pertenecía al círculo próximo de Carlos $\mathrm{V}$, ya indiqué en su momento que era la mejor obra de Giralte antes del retablo de la Capilla del $\mathrm{Obispo}^{24}$. Señalaba entonces el manierismo de los elementos de su traza, tanto en decoración como en formas estructurales.

Pero lo curioso del mismo es el hecho de que se trata de una solución acomodaticia entre lo más novedoso del momento y antiguas propuestas tradicionales. El hecho de que todo el retablo se envuelva en un guardapolvo cerrado, rematado en una forma similar a un arco carpanel, y que el calvario se sitúe fuera del retablo sobre la cornisa de la filacteria que recorre la capilla es una evocación de los retablos de capillas funerarias de finales del gótico y comienzos del siglo XVI, que generalmente iban encastrados en un arco de cantería. Este tipo de retablos particulares, como el de la capilla vallisoletana, siguió siendo utilizado por Felipe Bigarny en algunos de sus retablos documentados y atribuidos, como por ejemplo el de don Gutierre de Mier en la iglesia parroquial de Cervera de Pisuerga. De igual manera, su seguidor, Juan Ortiz el Viejo I, muy activo en el obispado de Palencia, realiza retablos de este tipo en San Cebrián de Buena Madre, que era el templo funerario de los Guevara, y en la capilla de San Ildefonso de la colegiata de Ampudia, asimismo recinto particular de don Alonso de Fuentes. Cualquiera de ellos pudo ser cono-

${ }^{21}$ Sobre el pleito de la Antigua, ver: Martí y Monsó, J.: Estudios..., op. cit., pp. 326-353; ParRAdo del Olmo, J. M.: Los escultores..., op. cit., pp. 115-118; Idem: Las tendencias..., op. cit., pp. 57-60.

${ }^{22}$ M ARTí Y Monsó, J.: Estudios..., op. cit., pp. 174 y sS.; P ARRADO DEL OlMO, J. M.: Las tendencias..., op. cit., pp. 65 y 66.

${ }^{23}$ Sobre el retablo del Dr. Corral, ver: P ORTela Sandoval, F. J.: La escultura del Renacimiento en Palencia. Palencia, 1977, pp. 264-266; P ARRAdo Del Olmo, J. M.: Los escultores..., op. cit., pp. 150-153.

${ }^{24}$ P ARRAdo del Olmo, J. M.: Los escultores..., op. cit., p. 152. 
cido por Giralte, pero al tratarse de un encar go particular, en todo caso, aquí hay que pensar en el gusto personal de un comitente que seguía buscando en las trazas de los retablos un nexo con el pasado, quizá por haber sido este tipo de estructura la habitual en las capillas funerarias de la nobleza castellana, con las que don Luis del Corral querría asimilarse ${ }^{25}$.

Al círculo de Francisco Giralte se ha atribuido un crucifijo que en 1987 se encontraba en la sacristía del convento de las Salesas Reales de Valladolid ${ }^{26}$. La dureza del modelado de la anatomía y la disposición del paño de pureza, que se entrecruza por delante de la pelvis no parecen propias del estilo del escultor, que nunca emplea este tipo de paño. En cuanto a la primera destaca la forma de destacar la musculatura en el vientre y los brazos, con formas muy marcadas. En cambio, la cabeza presenta unas formas suaves. El crucifijo de las Salesas se acerca más al crucifijo de la misma Cofradía de la Pasión, que hoy recibe la advocación de Cristo de la Cinco Llagas, el cual lo atribuí a la etapa juvenil de su cuñado Manuel Álvarez, en torno a 1550, momento en el que éste presenta muchos rasgos giraltescos en su estilo debidos probablemente a su colaboración en las obras encar gadas a su cuñado ${ }^{27}$. Por lo tanto, por el momento es preferible seguir atribuyéndolo al círculo de Manuel Álvarez, más que al de Francisco Giralte.

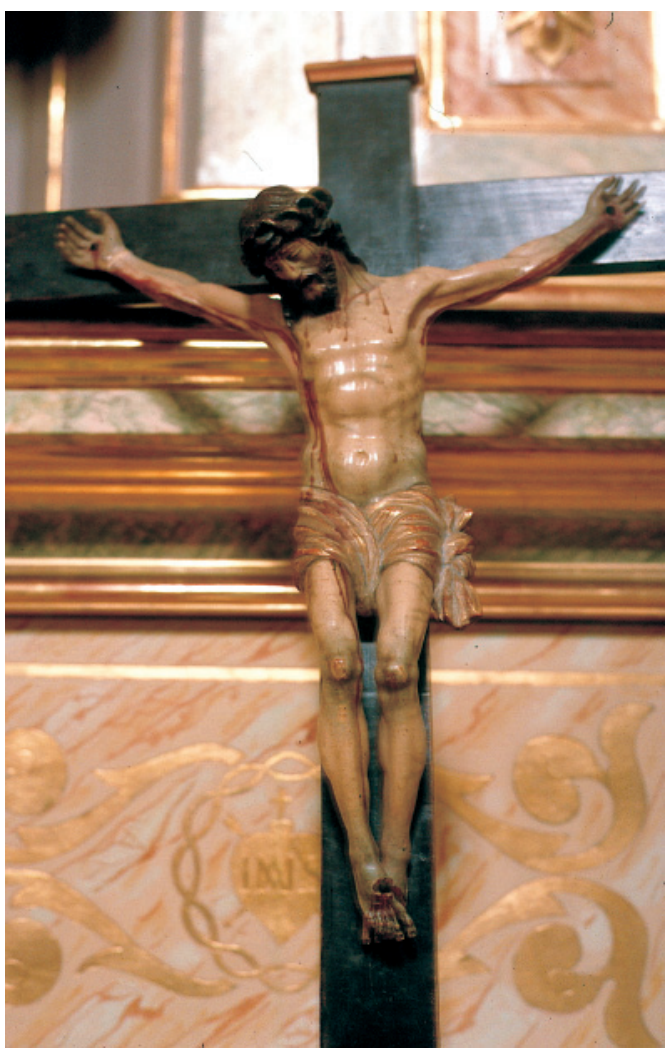

Fig. 5. Manuel Álvarez, círculo de. Crucificado, Valladolid. Convento de las Salesas.

Jesús María ParRado del Olmo Fac. Filosofía y Letras, Universidad de Valladolid

${ }^{25}$ Sobre el retablo de Cervera de Pisuerga, ver: Del Río DE LA Hoz, I.: El escultor Felipe Bigarny (h. 1470-1542). Salamanca, 2001, pp. 115-117. Sobre los otros retablos palentinos ver: P ORTEla SANDOVAL, F. J.: La escultura..., op. cit., pp. 88 a 91.

${ }^{26}$ M artín González, J. J. y D e la Plaza Santiago, F. J.: Catálogo Monumental de la Provincia de Valladolid. Monumentos religiosos de la ciudad de Valladolid (Conventos y Seminarios). Valladolid, 1987, p. 199, fig. 760.

27 El crucifijo de la cofradía de la Pasión se lo atribuí en: "El Crucifijo del Paso de las Siete Palabras". Boletín del Seminario de Arte y Arqueología, tomo LI, 1985, pp. 453-459. 